\title{
Flower morphology, floral development and insect visitors to flowers of Nepenthes mirabilis
}

\author{
TRI HANDAYANI \\ Center for Plant Conservation, Indonesian Botanic Gardens (Bogor Botanic Garden), Indonesian Institute of Sciences. Jl. Ir. H. Juanda No. 13 Bogor \\ 16122, West Java, Indonesia. Tel.: +62-251-8322187, Fax.: +62-251-8322187, email: irtri@yahoo.co.id
}

Manuscript received: 23 January 2017. Revision accepted: 17 October 2017.

\begin{abstract}
Handayani T. 2017. Flower morphology, floral development and insect visitors to flowers of Nepenthes mirabilis. Biodiversitas 18: 1624-1631. Nepenthes mirabilis Druce is a commercial ornamental pitcher plant belonging to the Nepenthaceae. This species is often used as a parent plant in artificial crossbreeding. The plant is also used in traditional medicine, rope-making, handicraft, and bouquets. Flower development and pollen maturity are important factors in pitcher plant crossbreeding. However, information about its flowering is still lacking. This study aimed to record the flower morphology, flower development, and faunal visitors to male inflorescences of $N$. mirabilis planted in Bogor Botanic Gardens, West Java, Indonesia. Twelve racemes of flowers were taken as a sample for observing the process of inflorescence development, while ten flowers on each raceme were observed for investigating the flowering pattern of individual flowers. The morphology of flowers, the process of inflorescence development, the flowering pattern for individual flowers, the number of open flowers, the longevity of anthesis, and the appearance of insect (and/or other faunal) visitors to flowers were observed and recorded, using naked eyes, a hand lens, and a camera. Six phases of inflorescence development were identified: inflorescence bud phase, raceme phase, the opening of the raceme-protecting sheath phase, inflorescence-stalk and flowerstalk growth phase, open flower phase and pollen maturity phase. Four phases of flower development were observed: growth of flower bud, the opening of tepals, pollen maturation, and flower senescence. The pattern of anthesis within an inflorescence was acropetal. The number of flowers per raceme was 56 to 163. The peak duration of anthesis of a flower was 11 days (30.7\% of flowers). The length of the raceme-stalks was $17-31 \mathrm{~cm}$. The length of the racemes was $23-38 \mathrm{~cm}$. The most common visitors to the flowers were stingless bees, Trigona apicalis.
\end{abstract}

Keywords: Flower, Nepenthes mirabilis, pitcher plant, pollen, raceme

\section{INTRODUCTION}

Nepenthes L. (Nepenthaceae) are tropical pitcher plants. According to Jebb and Cheek (1997) and Cheek and Jebb (2001) there are 87 Nepenthes species in the world.. Most of them are grown and distributed in Malesian Region. The species Nepenthes mirabilis Druce is a popular ornamental plant and has commercial value (Plachno 2007). The species is often used as a parent plant in artificial crossbreeding. This plant is also used in traditional medicine, rope-making, handicraft, and bouquets (Handayani et al. 2005, 2012). It is one of the most widely known species in the genus. It has a broad distribution in China, Vietnam, Thailand, Peninsular Malaysia, Indonesia (Sumatra, Java, Borneo), Philippines, Sulawesi, Maluku, New Guinea, Palau Island and Australia (Cheek and Jebb 2001; Hua and Li 2005).

Nepenthes mirabilis is classified as lower risk (least concern) based on IUCN and as not threatened based on WCMC (Cheek and Jebb 2001). In Indonesia this species is protected by Peraturan Pemerintah (Government Law) No.7, 1999 about protection and conservation of plant and wildlife (Mogea et al. 2001). Therefore the trade of this plant is controlled internationally under CITES (D'amato 1998).
In nature, this species is most abundant in slightly seasonal habitats, such as swamps. It is equally common on alkaline and acidic soils. It does not compete well with other Nepenthes, so rarely is found in places where other Nepenthes species are abundant (Clarke 2001). Plants are dioecious (Phillipps and Lamb 1996; D'amato 1998) with each individual plant producing male flowers or female flowers only (Cheek and Jebb 2001; Clarke 2001).

The flowering patterns in lowland species are seasonal, while the mountain species flowered continuously throughout the year (Clarke 2001 ). Nepenthes mirabilis is one of the pitcher plants that is easily cultivated (Handayani et al. 2012). It is a climbing plant that blooms quite frequently, with individual plants producing a significant quantity of flowers. Plants generally bloom after climbing to a height where pitchers are produced (Clarke 2001; Cheek and Jebb 2001). Flowers are borne on peduncles which have simple pedicels. Male flower buds are rounded, while the female flowers have ovaries that are elliptical in shape. In general, the number of male flowers in a raceme of a male plant is more than the number of female flowers in the racemes of a female plant (Clarke 2001). D'amato (1998) reported about $70 \%$ of Nepenthes plants in forests produce male flowers, and only 30\% produce female flowers. Male flowering plants are also more often found among cultivated Nepenthes mirabilis. 
Pollination occurs when pollinators transfer pollen from male flowers to the stigma of a female flower (Clarke 2001). The olfactory signals from flowers play an important role in the specific attraction of pollinators. Many pollinators learn the particular scent signals of different species to recognize those flowers offering the highest quality rewards. However, not all floral rewards are available for all the potential visitors in a community (Farre-Armengol 2015). Pitcher plants attract insects by providing nectar throughout the year (Pavlovic et al. 2007; Giusto et al. 2008), by the scent emitted by the flowers (Pavlovic et al. 2007; Giusto et al. 2008), and by the attractiveness of the pitchers and brightly colored flowers (Hua and Li 2005). Flowers attract visitors specifically by the presentation of nectar and pollen. Nectaries and pollen are a reward for the insects and animals visitors pitcher (Hua and Li 2005; Bouer et al. 2007, Plachno 2007, FarreArmengol 2015). Nectar is a sugar-rich liquid whose production in flowers is highly related to the energy requirements of pollinator species, especially when flowers are pollinated by only one or a few species (Clarke 2001; Farre-Armengol 2015). Kato (1993) and Owen et al. (1999) reported that the nectar is particularly attractive to ants. The tepals of the flowers are equipped with glands to produce nectar (Phillipps and Lamb, 1996). The shape of the tepals is rather cupped, intended for nectar containers. Nectar is a reward, enticing insects and animals to visit the flowers (Hua and Li 2005). The flowers can be located on any above-ground part of the plant (Plachno 2007).

Information regarding the biology of flowering in pitcher plants is still very limited. Kato (1993) conducted research into the flower biology of Nepenthes gracilis. Its flowers are pollinated by moths and flies. Moran (1993) cited in Clarke (2001) reported that insect visitors to $N$. rafflesiana are beetles, ants, moths, and flies. The flowering biology of $N$. ampullaria, $N$. gracilis and $N$. reinwardtiana in West Sumatra (Indonesia) has also been reported on by Meriko (2012). The flowers of these species bloom one by one or in groups, starting from the base toward the tip.

On the other hand, information on the flowering biology of $N$. mirabilis is lacking. The purpose of this current study was to identify the morphology of flowers, the process of inflorescence development, the flowering pattern for individual flowers, the number of flowers, the longevity of anthesis, and the appearance of insect (and/or other faunal) visitors to flowers. Understanding the flower morphology, flower development, and the kinds and numbers of insect visitors to the flowers will be useful in developing crossbreeding and propagation programs for this plant.

\section{MATERIALS AND METHODS}

\section{Time and place}

This research was carried out at Bogor Botanic Gardens, West Java, Indonesia from January 2015 to June 2015. The altitude is about $260 \mathrm{~m}$ asl, relative humidity was $34-80 \%$, and the temperature was $25-39^{\circ} \mathrm{C}$.

\section{Plant materials}

Nepenthes mirabilis plants studied in the Gardens were part of a collection from Kalimantan that has been grown in the Bogor Botanic Gardens since 2004. Twelve staminate inflorescences were observed. Ten individual flowers from each inflorescence were investigated for flowers pattern. Observations of flower morphology, flower development, and flower visitors were made every day.

\section{Observation of flower morphology}

Observations of raceme and flower morphology were made on male flowering plants. Flowers were examined in terms of the type of inflorescence and the features of individual flowers, including their peduncles, pedicels, tepals, and stamens. Determination of the morphological characters of flowers was made by naked eye. The peduncle length, pedicel length, tepal length, tepal width, and stamen length were measured with a ruler.

\section{Observation of floral development}

These observations focused on four aspects: the inflorescence development process; the pattern of anthesis of individual flowers; the number of flowers; and the longevity of individual flowers. Twelve racemes of flowers were taken as a sample for observing the process of inflorescence development, while ten flowers on each raceme were observed for investigating the flowering pattern of individual flowers. Observation of the process of inflorescence development started from inflorescence bud enlargement until all individual flower had opened. Data were collected from when the inflorescence emerged from out of its inflorescence-protecting leaf (sheath) until when all individual flowers had opened. The stages of the process of inflorescence development were photographed using a Camera Canon Power Shot SX160IS. The flowering patterns of individual flowers were observed from the time of opening of the tips of the tepals until the time when the flowers withered and dried down. The number of flowers at anthesis (when the tepals of the flowers were open) were counted every day. The longevity of anthesis was calculated from the first opening of a flower until the time when the flower withered and dried.

Observation of the appearance of insects and other fauna

Insects and/or faunal visitors to the flowers were generally recorded at 06.00 to $10.00 \mathrm{~h} ; 10.00$ to $14.00 \mathrm{~h}$, and 14.00 to $18.00 \mathrm{~h}$. Visitors were identified through direct observation and grouped into bees, ants, beetles, moths, flies, wasps, butterflies or spiders. Determination of insects and/or faunas both as pollinator or not were recorded by using the foraging and feeding behaviors of flower visitors. Photograph taken during the visits.

\section{RESULTS AND DISCUSSION}

\section{The flowering morphology}

Nepenthes are dioecious plants. Most of the Nepenthes collection in Bogor Botanical Gardens only produce male flowers. D'amato (1998) reported that it is male flowers 
that are most often produced in Nepenthes raised by ex situ cultivation. The inflorescence of $N$. mirabilis generally appears at the tip of the stem or branches. The flowering season for the Nepenthes collection in Bogor Botanical Gardens usually occurs between March and June. The growth of inflorescence buds was observed in JanuaryMarch, the flowers bloomed in March-May, and then the flowers withered and dried in May-June.

The male inflorescence is a raceme, with a main axis, and with partial peduncles branching off, bearing 1-2 flowers, each with its own pedicel (Figure 1). The length of the inflorescence stalk (peduncle) is $17.0-31.0 \mathrm{~cm}$. It has a brownish green color. The length of the raceme is 23.0$38.0 \mathrm{~cm}$, with a brownish color. The individual pedicels are green in color and 1.0-2.0 cm in length. The form of the flower is simple with four tepals. The shape of the tepals is orbicular-elliptical and rather cupped. The color of tepals is reddish-purple. The length of tepals is $0.4-0.7 \mathrm{~cm}$, while the width is $0.3-0.6 \mathrm{~cm}$. The length of the staminal column is $0.3-0.6 \mathrm{~cm}$. It has a dark green-dark red color. At the tip of the staminal column are yellow-colored anthers. The inflorescence-stalks, peduncles, and tepals are all covered with soft hairs.

\section{The development of flowering \\ The process of inflorescence development}

The process of inflorescence development starts with the enlargement of an inflorescence bud and continues until all individual flowers have opened. The inflorescence bud is easily distinguished from vegetative shoots because of the enlargement of the buds. From the time of enlargement of the inflorescent bud until the full opening of all individual flowers, there are five phases: growing of inflorescence bud phase, growing of raceme phase, the opening of the inflorescence-protecting sheath phase, inflorescence-stalk and flower-stalk growth phase, anthesis phase, and pollen maturity phase (Figure 2).

\section{Phase 1. Growing of inflorescence bud phase}

This phase is first characterized by a reduction in the size of the leaves growing at the apex of a stem or branch. One leaf, the sheath that will protect the developing inflorescence, then begins to expand in contrast to the other leaves. This enlargement of the sheath is indicative of the initiation of the inflorescence within. The color of this encircling leaf is light green, covered by glaucous hairs.

\section{Phase 2. Growing of raceme phase}

This phase is characterized by the full enlargement of the inflorescence-protecting leaf. The size of the raceme enlarges towards the tip of this sheath. The middle part of the sheath bulges the widest, compared to the base and the tip. The color of the leaf is light green, covered by glaucous hairs. The inflorescence-stalk (peduncle) located inside the base of the sheath, while the tip of the raceme is inside the apex of the sheath.

\section{Phase 3. Opening of the inflorescence sheath phase}

This phase is characterized by the raceme emerging from its protecting leaf. After the raceme reaches full size, the edges of the sheath open gradually until fully open. After that, the raceme will be emergent and freed from the inflorescence sheath. The individual flowers at this point are still clustered together. The color of the flowers is silvery, silvery brown or silver-green. In our experiment, this phase occurred one month after the inflorescence shoot was first apparent in its protective leaf.

\section{Phase 4. Growing of raceme-stalk and flower-stalk phase}

This phase is characterized by the elongation of the raceme-stalk and individual flower-stalks. After the sheath opens, both raceme-stalk and the flower-stalks grow continuously. Finally, the individual flowers that are still clustered together, become separated one from the other. The length of the raceme-stalk emerging from the inflorescence sheath is $6-8 \mathrm{~cm}$. The raceme-stalk elongates until the time when the individual flowers bloom. The longest raceme-stalk observed was $31 \mathrm{~cm}$. Early on, the length of the raceme is only $5 \mathrm{~cm}$, but after the individual flowers bloom the raceme reaches $38 \mathrm{~cm}$ in length.

At the time when the raceme is just emerging from the sheath, the flowers are still clustered together. With subsequent growth, the individual flower-stalks (pedicels) grow longer, which means ultimately that the flowers are no longer clustered together. The pattern of a flower blooming within an inflorescence is from the base toward the tip. From 1 to 5 days, the flowers on the lower third of the raceme separate from each other. By 5-8 days, twothirds of the raceme has its flowers separated from one another, while by days 8-11 all the individual flowers are separate.. The separation of individual flowers starts from the base and progresses towards the tip of the raceme In our experiment, it occurred 2-12 days after the young sheath opened. The color of the raceme at this point was silver or silver-green.

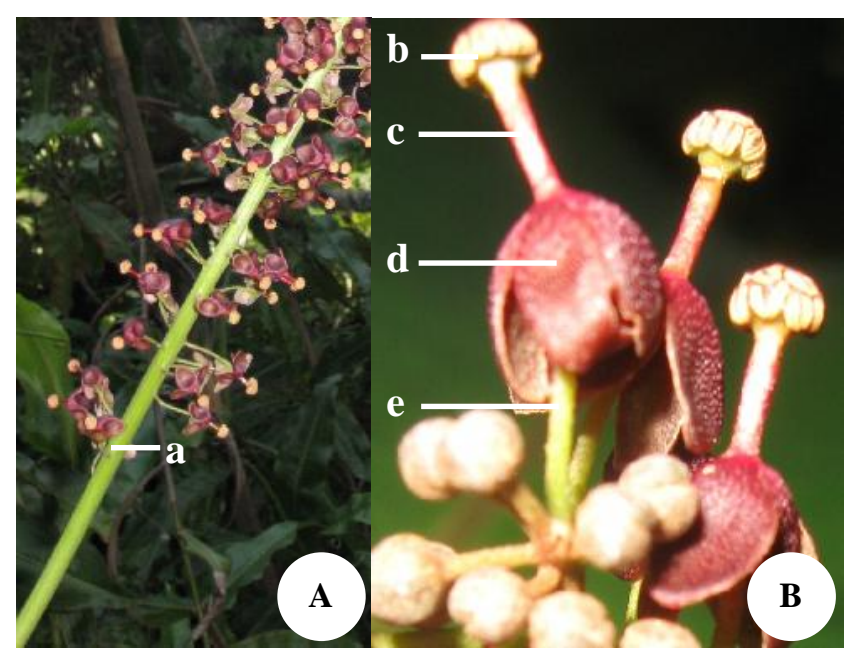

Figure 1. Parts of male inflorescense. A. Male inflorescense, B. Male flowers, a. Inflorescense stalk, b. Anters, c. Column, d. Tepal, e. Pedicle 

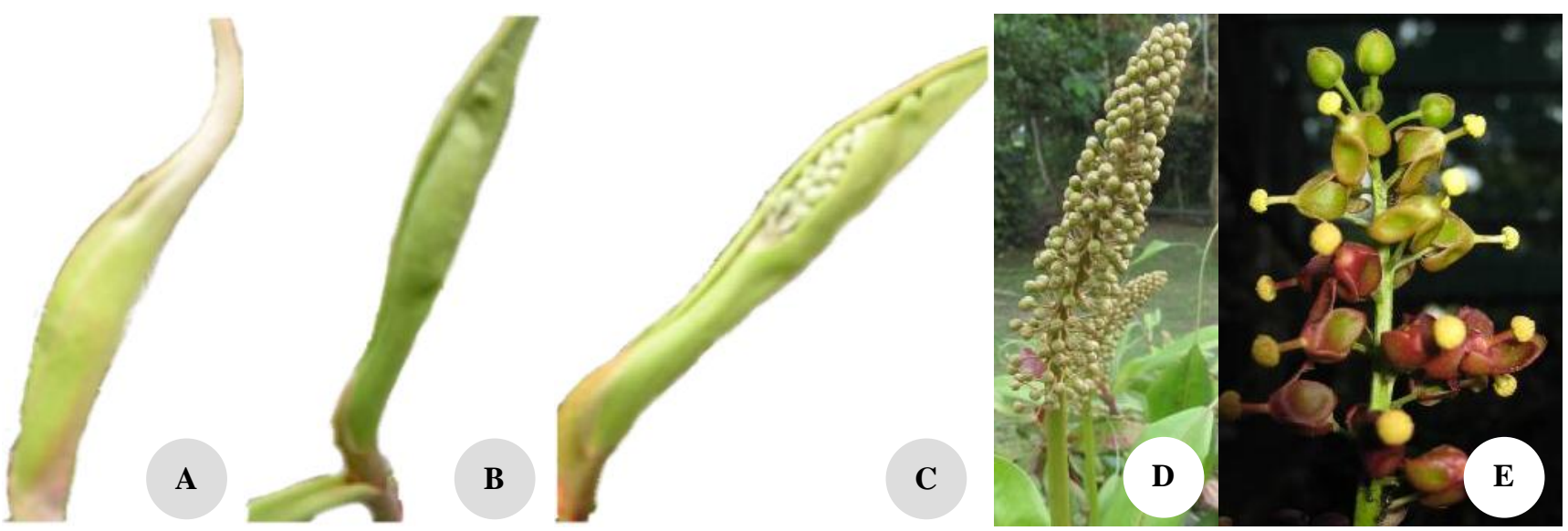

Figure 2. The process of inflorescence development. A. First phase, W1, B. Second phase,W 1-3, C. Third phase, W 3-4, D. Fourth phase, W 5-6, E. Five-six phase, W 6-8. W: week

\section{Phase 5. Opening of flowers phase}

This phase is characterized by the opening of tepals of the individual flowers. This phase starts with the opening of the tepals at their apices until the flower tepals are fully opened. After the tepal tips open, the light yellow anthers appear in the opening space between the tepal apices. Tepals open further until fully apart. The tips of the sepals then curve outwards and downwards towards the pedicel. In our experiment, this occurred 2-12 days after the leafwrapper opened. The duration of the opening of the raceme until it dries was from 22-49 days.

\section{Phase 6. Pollen maturity phase}

In our observations, the maturation of pollen generally occurred a day after the opening of a flower. The maturation of the stamens was followed by the rupture of the anthers and the appearance of pollen on the anthers. The time of stamen maturation began in the afternoon. The amount of visible pollen was greater at night than in the daytime. This. would suggest that the flowers are pollinated by nocturnal insects? It should be observed and experiment further. ). This phase occurred 1-2 days after the blooming of flower (i.e. after the opening of the tepals).

\section{The pattern of individual flower blooming}

Nepenthes mirabilis flowers are borne on partial peduncles that have 1-2 flowers each with its own pedicel. A male flower of Nepenthes generally consists of flowerstalk, tepals, staminal column, and anthers. Flowers open throughout the day and the pollen is shed some hours later. Male $N$. mirabilis flowering starts from the raceme base with a total set of 56-163 flowers per inflorescence. A variable number of flowers (1-40 flowers) open each day, starting from the base of the inflorescence. The anther cluster releases pollen after the tepals open.

Hua and $\mathrm{Li}$ (2005) reported that when Nepenthes mirabilis is flowering in field, the odor is almost undetectable. It is unknown where the odor is released from, but they explained that it was from nectaries on tepals. They suggested making further observation and experiment of this species to prove that the odor emanating from the flower. From my observation, the odor release from the flower, if the flower tip opened a fragrant smell like the odor of pandanus leaves release from the flower. Then, the yellow pollen is often shed directly into the tepals. As soon as the flower tip opened, the insects visit the flower.

In this research, there were four phases detected in flower development: growing of the flower bud, opening of tepals, pollen maturation, and flower senescence.

\section{Phase 1. Growing of the flower bud}

Initial growth of flower buds occurs in the inflorescence, protected by the inflorescence sheath. Each raceme consists of 56-163 flowers and the growing of the individual flowers is in line with the growing of the whole inflorescence. After the opening of the protecting leaf wrapper, the growth of the flowers appears faster. The flower buds are ovoid. Their color is green covered by brownish hairs. The length of each pedicel is $1.0-2.0 \mathrm{~cm}$. The pedicel is greenish-yellow and is covered by brownish hairs.

\section{Phase 2. Opening of the tepals}

Tepals are $0.4-0.7 \mathrm{~cm}$ long and $0.3-0.6 \mathrm{~cm}$ wide. The process of a flower blooming is presented in Figure 3. The process starts with the opening of the tips of the tepals. The tepals open wide until their positions are almost perpendicular to the stamens. With increasing age of the flowers, the tepals reflex backward arching down towards the flower-stalk to almost cover the flower-stalk. The tepals gradually dry out during flower blooming. Their inner, adaxial surfaces are usually reddish-green, reddish-brown, or yellowish-green, when they open on first day, turning reddish-purple post full blooming. On the other hand, their outer, abaxial surfaces are yellowish-green or reddishbrown when they open, turning greenish-red, reddishpurple or greenish-red. 


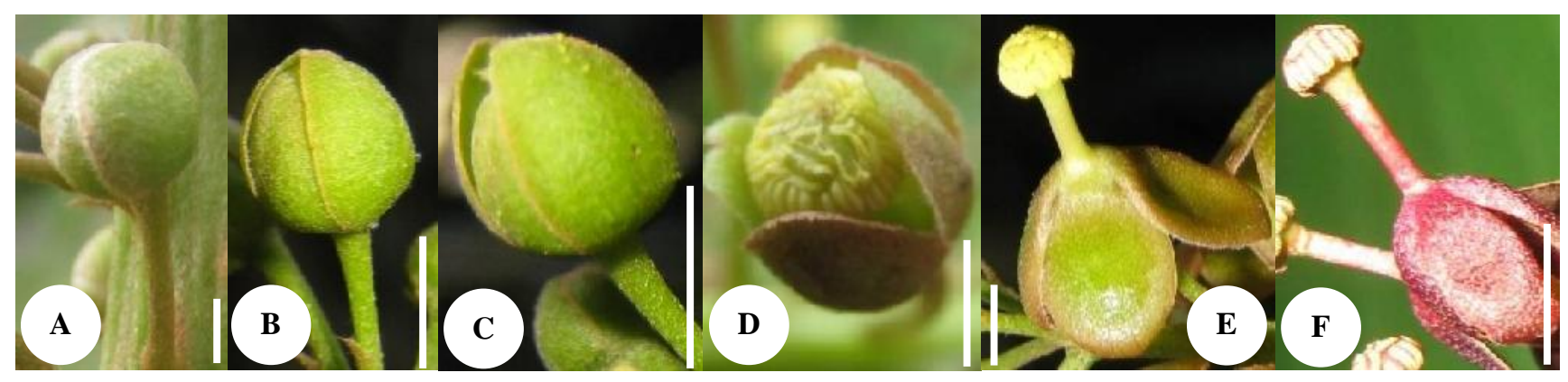

Figure 3. The process of a flower blooming. .A-B. Closed flower bud. C-D. Opening tip tepals. E. Fully opening tepals. F. Post blooming flower. Bar: $0.5 \mathrm{~cm}$

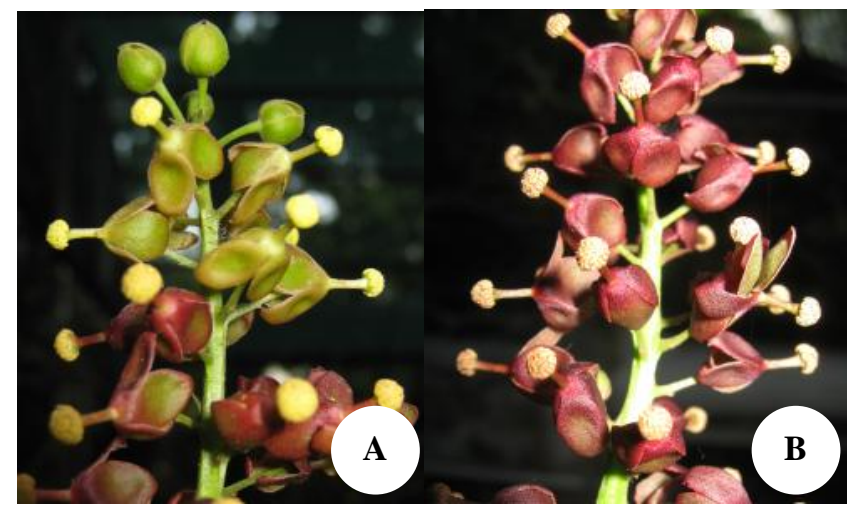

Figure 4. A. Pollen maturation phase. B. Senescense phase

\section{Phase 3. Pollen maturation}

Flowers that will bloom are characterized by the stretching of the tepals and the opening of their tips. One to two days after these signs, the flower usually bloom. The yellow anthers usually appear when the tips of the tepals are opening. Stamens are more apparent as the tepals open out.

The anther cluster releases pollen after the tepals open (Figure 4.A) The release of pollen from the anthers lasts for 2 days. The flower-stalk, tepals, and stamens change during the progress from blooming to post-blooming. The flowerstalk is usually brownish-green on the first day of a flower blooming, turning reddish-green or brownish-green, 2-7 days later. After the seventh day, the flower-stalk turns dark green. The color of the staminal column and anthers change after the maturation of pollen. The column is usually light yellow when in full bloom, turning light red or purplish-yellow a day later. Two days later the column turns dark red to purplish-red, while the anthers are light yellow or yellow during blooming, turning dark yellow a day later. Two days later, the anthers turn dark yellowpurplish (Figure 4.B).

\section{Phase 4. Senescence of the flower}

This phase is characterized by the drying out of the anthers. The flower-stalk, tepals, and stamens have reached their maximum size and so do not grow again. Next, these parts wither and dry up, starting from the anthers and progressing to the flower-stalk. In our observations, anthers began to dry out 9-13 days after the start of blooming of the flower. All parts of the flower had dried down 49 days after blooming in the quickest maturing flowers.

\section{The number of flowers in bloom}

Flowers bloom uniformly, starting from the base to the tip. The number of flowers that bloom in a raceme each day varies significantly, from 2 to 40 flowers per day (Figure $5)$. In general, only a few flowers bloom initially, with the number per day peaking at about day 3 to 4 . Later, the blooming tends to be stretched out with fewer open flowers per day. The accumulated number of flowers that open per raceme ranges from 56 to 163 flowers (Figure 6). The total flower number per raceme is related to its length. The results of my observation indicate that for racemes less than $30 \mathrm{~cm}$ in length, less than 100 flowers are produced. Racemes more than $30 \mathrm{~cm}$ long produce more than 100 flowers.

The type and amount of insect visitors to the flowers were observed to be related to the number of blooming flowers per raceme. The greater the number of flowers that bloom in a raceme the greater the quantity of pollen and nectar released, and the more favorable are the conditions for visitors to forage for nectar or pollen. When a flower is in full bloom, the color of the four tepals is bright (reddishbrown), so attracting insects to visit the flower. The sweet smell of the flowers is also an attractant for insects. Tepals are one of the sources of nectar in Nepenthes The main visitors in Nepenthes flowers are insects. Visual signals are important in attracting diurnal insects to flowers. Highcontrast color pattern help pollinators orient themselves to reach the nectar source. Among the common floral pigments are antocyanins (blue, red) and carotenoids (Chittka and Menzel 1992; Moran et al. 1999; Clarke 2001).

\section{The longevity of blooming in individual flowers}

The longevity of blooming in flower is the time from the beginning of its tepals opening until the time when the flower dries. This research found that the longevity of flower blooming was from 10-15 days. The mode for the distribution of longevity was at 11 days, with $30.7 \%$ of all flowers observed having a longevity of 11 days (Figure 7). Although the duration of the blooming process for an individual flower is quite long, the duration of pollen maturity is only about 1-2 days. This means that potential 
pollinators have only a relatively short time in which mature pollen can be obtained and can contribute to the pollination of flowers on female plants.

\section{Flower visitors}

Nepenthes is a dioecious (Chua 2000), obligate crosspollinated species that depends on insect pollinators. It is well known that olfactory signals from flowers play an important role in the specific attraction of pollinators. Nepenthes flowers attract visitors using color, odor, nectaries and pollen. These species seem to be mainly pollinated by flies (Calliphoridae, Muscidae and Syrphidae) and moths. However, Jurgen et al. (2001) found that Formicidae was the dominant prey category present in the pitchers, accounting for between $50-90 \%$ in the ground pitchers. Several insects visit Nepenthes flowers, but the most effective pollinators are moths, flies, wasps, and butterflies (Plachno 2007). Kato (1993) reported that flowers of $N$. gracilis are pollinated by moths and flies. Clarke (2001) reported that insect visitors on $N$. rafflesiana are beetles, ants, moths, and flies. In my observations, from the time that the tips of flower tepals opened, numerous insects visited Nepenthes flowers between 06.00 a.m and 18.00 p.m. The staminate inflorescences were visited by a variety of flower visitors, ranging from stingless bees (Trigona spp), ants, wasps, flies (hoverflies and green bottles), moths and mosquitoes (Table 1, Figure 8).

Although many of these types of insects visited the flowers, some of those visitors appeared not necessarily to be effective pollinators; feeding on pollen but not necessarily transferring it to other flowers. My observations suggest that stingless bees were effective gatherers of pollen, but not necessarily effective pollinators, with their hind legs often carrying away the yellow pollen (Figure 9A). Ants and flies were common flower visitors (Figure 9B) . They ate nectar, disturbing other flower visitors, sometimes damaging pollen. Ashmand and King (2005) reported that ants could be effective pollinators especially in plant species with a low, dense, flowering stature. The positive relationship between ant and plant can be seen in ant-plant associations the ants defend their resources and thus protect their plant partners against herbivores (Merbach et al. 2007). In other situation, ants can act as antagonists, by removing nectar, disrupting the visitation of effective pollinators, and reducing pollination. According to Clarke (2001), several visitors visit Nepenthes flowers during both day and night for nectar and pollen.

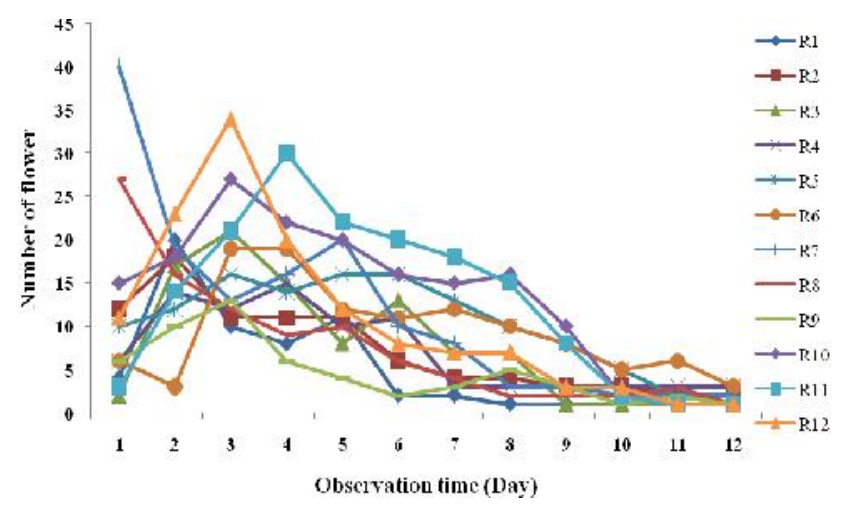

Figure 5. The number of flowers in bloom per day in twelve racemes observed (R1-12= Raceme 1-12).

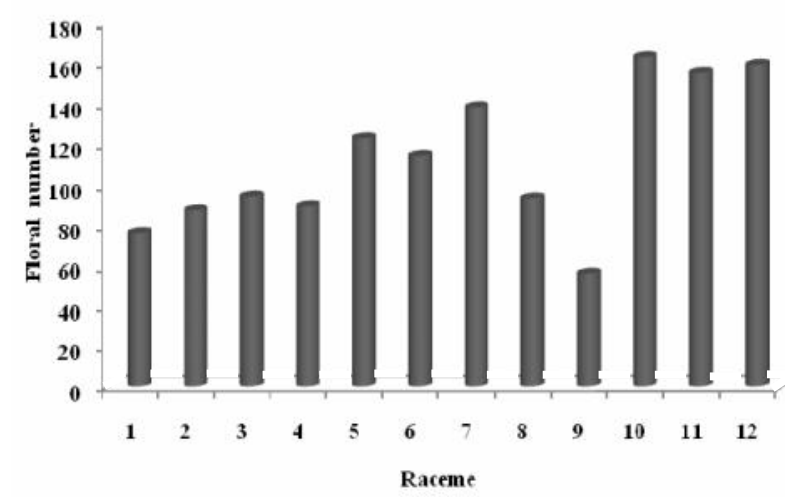

Figure 6. The accumulated number of flower that bloomed in each of 12 racemes

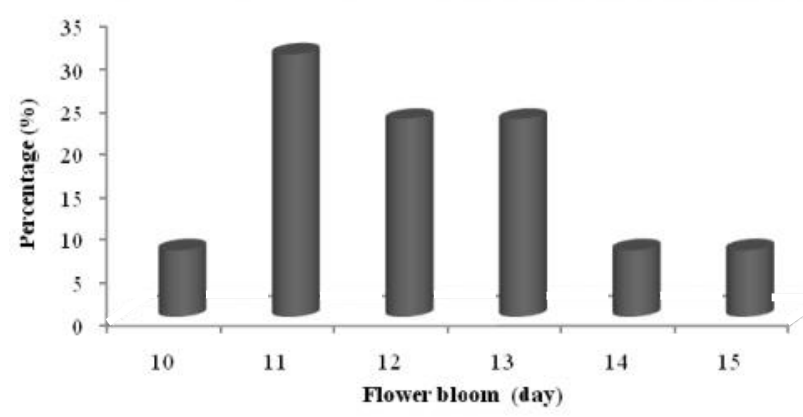

Figure 7. Distribution for longevity of a flower in bloom

Table 1. The common visitors to the male flowers of N.mirabilis

\begin{tabular}{lll}
\hline $\mathbf{0 6 . 0 0}$ to $\mathbf{1 0 . 0 0} \mathbf{~ h}$ & $\mathbf{1 0 . 0 0}$ to $\mathbf{1 4 . 0 0} \mathbf{~ h}$ & $\mathbf{1 4 . 0 0}$ to 18.00 \\
\hline Whitish-brown spider & White spider & Trigona spp. (stingless bees) \\
Yellow spider & Yellow spider & Ants \\
Ants & Green spider & Yellow spider \\
Trigona spp (stingless bees) & Ants & Hoverflies \\
& Hoverflies & Green bottles (fly) \\
& Green bottles (fly) & Mosquitoes \\
& Trigona spp (stingless bees) & \\
& Aphis dorsata (bee) & \\
& Wasps & \\
\hline
\end{tabular}




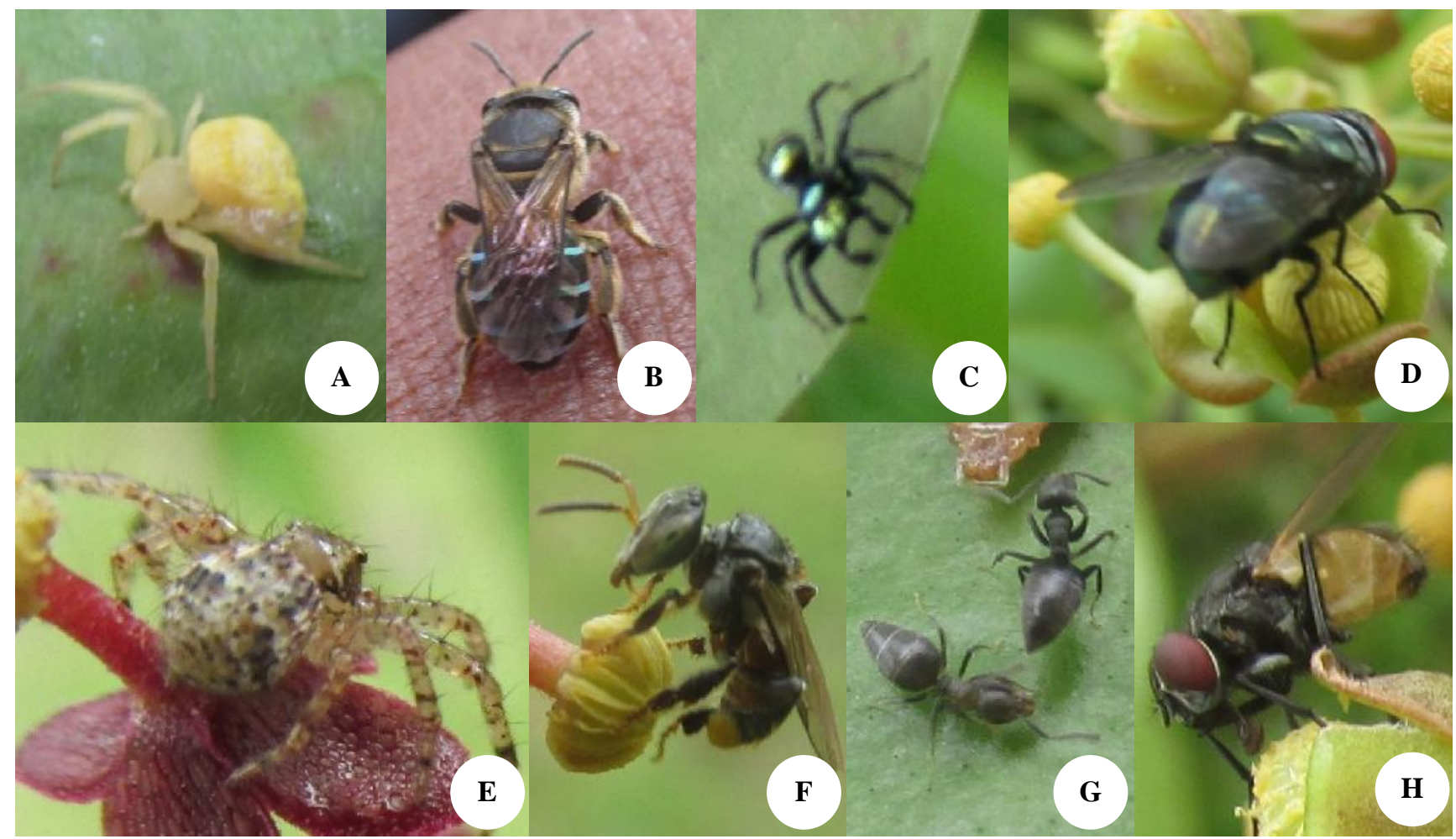

Figure 8. The common visitors to the male flowers of N. mirabilis, A. Yellow spider, B. Aphis dorsata, C. Green spider, D. Green bottles, E. Whitish spider, F. Trigona sp., H. Hoverfly

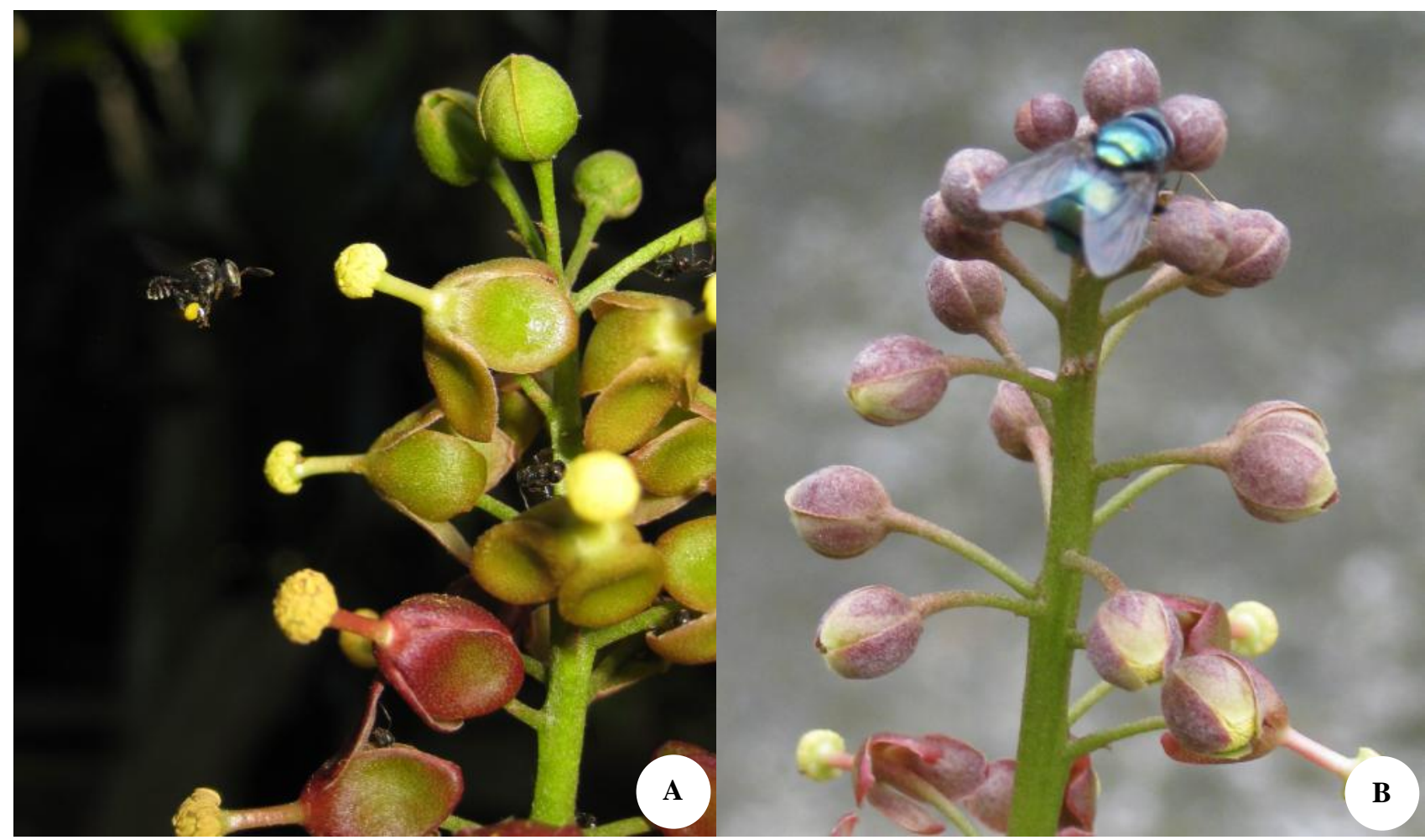

Figure 9.A. Stingless bees with yellow pollen in it hind leg. B. Green bottles on male flowers 
In summary, the present study has shown that the process of inflorescence development can be described in six phases while the blooming pattern for individual flowers is most usefully described in four phases. The number of flowers blooming within the flowering period of a raceme was found to vary from 2-40 per day, while the total number of flowers that bloomed over the lifetime of a raceme varied from 56 to 163 . The duration of a flower from beginning to the end of blooming was 10-15 days. The staminate inflorescences were visited by a variety of flower visitors, ranging from stingless bees (Trigona spp.), ants, wasps, flies (hoverflies and green bottles), moths and mosquitoes. The possible pollinators are stingless bees.

\section{ACKNOWLEDGEMENTS}

The author is grateful to Dr. Graham Eagleton (Australian Volunteer for International Development) for helpful discussion and reviews the manuscript's English and correcting the language. I also would like to express my thanks to Dr. Ruhyat Partasasmita, for his generous reading and discussion of the manuscript. Sincere thanks are due to Sudarsono (technician of the Bogor Botanic Gardens) for his help in caring for the Nepenthes plants.

\section{REFERENCES}

Ashman TL, King EA. 2005. Are flower-visiting ants mutualists or antagonists? A study in Gynodioecious wild strawberry. Am J Bot 92 (5): 891-895.

Bauer U, Bohn HF, Federle W. 2007. Harmless nectar source or deadly trap: Nepenthes pitchers are activated by rain, condensation, and nectar. Proc R Soc B Biol Sci. 275 : 259-265.

Cheek M, Jebb M. 2001. Nepenthaceae. Flora Malesiana, Series I, Vol. 15.

Chittka L, Menzel R. 1992. The evolutionary adaptation of flower colours and the insect pollinators colour vision. J Comp Physiol A $171: 171$ 181

Chua LSL. 2000. The pollination biology and breeding system of Nepenthes macfarlanei (Nepenthaceae). J Trop For Sci 12 (4):635642.
Clarke C. 2001. Nepenthes of Sumatra and Peninsular Malaysia. National History Publications. Natural History Publications (Borneo) Sdn.Bhd., Kota Kinabalu

D'amato P. 1998. The savage gardens. Ten Speed Press. Berkeley, California.

Farre-Armengol G, Filella I, Llusia J, Penuelas J. 2015. Relationships among floral VOC emissions, floral rewards and visits of pollinators in five plant species of a Mediterranean shrubland. Plant Ecol Evol 148 (1): $90-99$.

Giusto BD, Brosbois V, Fargeas E, Marshall DJ, Gaume L. 2008. Contribution of pitcher fragrance and fluid viscosity to high prey diversity in a Nepenthes carnivorous plant from Borneo. J Biosci 33 (1): 121-136.

Handayani T, Latifah D, Dodo. 2005. Diversity and growth beharviour of Nepenthes (pitcher plants) in Tanjung Putting National Park, Central Kalimantan Province. Biodiversitas 6 (4): 248-252

Handayani, T, Isnaini Y, Yuzammi. 2012. Mirabilis pitcher plant (Nepenthes mirabilis Druce) and cultivation techniques. Center for Plant Conservation Botanic Gardens, Indonesian Institute of Sciences. [Indonesian].

He J, Zain A. 2012. Photosynthesis and nitrogen metabolism of Nepenthes alata in response to inorganic NO3 and organic prey $\mathrm{N}$ in the greenhouse. Research article. ISRN Botany. Article ID 263270. Page: 1-8. DOI:10.5402/2012/263270. Accession 06 Feb 2017.

Hua Y, Li H. 2005. Food web and fluid in pitchers of Nepenthes mirabilis in Zhuhai, China. Acta Bot Gallica 152 (2): 165-175.

Jurgen AJ, Sciligo A, Witt T, El-Sayed AM, Suckling DM. 2011. Pollinator-prey conflict in carnivorous plants. Biol Rev. 87: 602-615.

Kato M. 1993. Floral biology of Nepenthes gracilis (Nepenthaceae) in Sumatra. Am J Bot 80 (8): 924-927.

Merbach MA, Zizka G, Fialaz B, Merbach D, Booth WE, Maschwitz U. 2007. Why a carnivorous plant cooperates with an ant-selective defense against pitcher-destroying weevils in the myrmecophytic pitcher plant Nepenthes bicalcarata Hook.F. Ecotropica 13: 45-56.

Meriko L. 2012. Flowering biology of Nepenthes spp. (N. ampullaria, N. gracilis and $N$. reinwardtiana). E-Jurnal Pelangi STKIP PGRI 4 (2): 1-16. [Indonesian]

Mogea JP, Gandawijaya D, Wiriadinata H, Nasution RE, Irawati. 2001 Rare plants of Indonesia. Research Center for Biology, Indonesian Institute of Sciences. [Indonesian].

Moran JA, Booth WE, Charles JK 1999. Aspects of pitcher morphology and spectral characteristics of six Bornean Nepenthes pitcher plant species: implications for prey capture. Annals of Botany 83: 521 \pm 528

Owen Jr TP, Lennon KA. 1999. Structure and development of the pitchers from the carnivorous plant Nepenthes alata (Nepenthaceae). Am J Bot 86 (10): 1382-1390.

Phillipps A, Lamb A. 1996. Pitcher-plants of Borneo. Natural History Publications (Borneo) Sdn.Bhd., Kota Kinabalu.

Pahlovic A, Masarovic E, Hudak J. 2007. Carnivorous syndrome in Asian pitcher plants of the genus Nepenthes. Ann Bot 100 (3): 527-536.

Plachno BJ. 2007. "Sweet but dangerous": nectaries in carnivorous plants. Acta Agrobotanica 60 (2): 31-37. 